Alma Mater Studiorum - Università di Bologna DEPARTMENT OF ECONOMICS

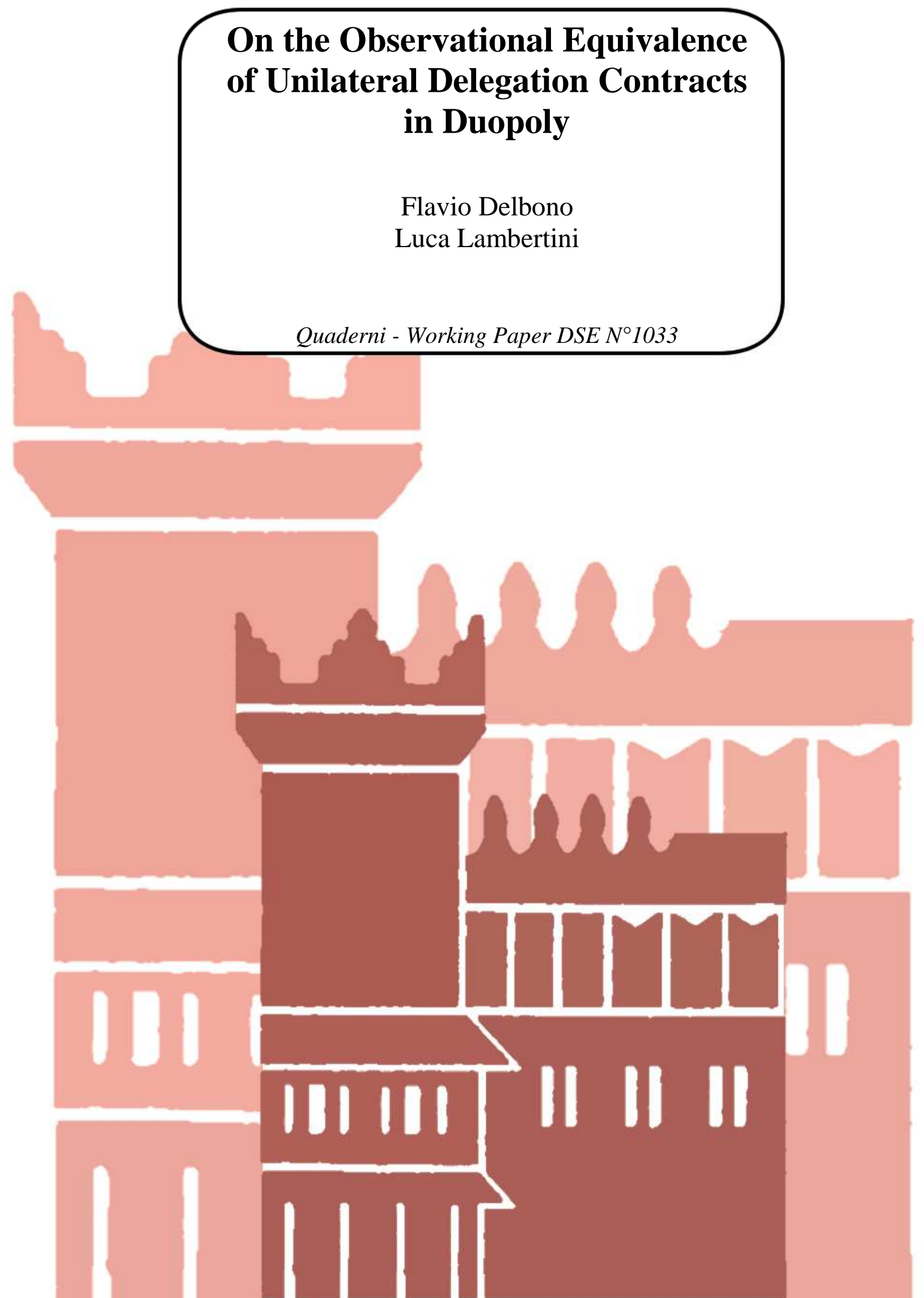




\title{
On the Observational Equivalence of Unilateral Delegation Contracts in Duopoly
}

\author{
Flavio Delbono ${ }^{\#}$ and Luca Lambertini ${ }^{\S}$ \\ \# Department of Economics, University of Bologna \\ Piazza Scaravilli 2, 40126 Bologna, Italy \\ flavio.delbono@unibo.it \\ $\S$ Department of Economics, University of Bologna \\ Strada Maggiore 45, 40125 Bologna, Italy \\ luca.lambertini@unibo.it
}

\begin{abstract}
In a Cournot duopoly, if only one firm hires a manager while the other remains entrepreneurial, the Cournot-Stackelberg equilibrium emerges, with the managerial firm as the leader. This happens under at least three different delegation schemes. We illustrate the different meachanisms driving this outcome through the analysis of the map of best replies at the market stage.
\end{abstract}

JEL Codes: D43, L13, L21

Keywords: delegation; comparative performance; market share; sales; Cournot competition 


\section{Introduction}

Since the seminal research by Baumol (1958) and Schelling (1960), the literature on strategic delegation has been growing significantly and various types of managerial incentives have been put forward. We may roughly group such incentives into three types, depanding on whether, in addition to its own profits, a firm's objective function includes also output (or revenue), market share or the rival's profits.

Detecting which actual managerial incentives are subministered by owners in modern corporations is an important empirical question. ${ }^{1}$ Not less important, however, is the understanding of which type of delegation contract would be selected from a menu of different types. Jansen et al. (2009) investigate the strategic choice of managerial incentives in a Cournot industry within the aforementioned threefold menu, and show that, at the subgame perfect equilibrium, owners hire managers through contracts based on comparative performance, the latter being Pareto-efficient for firms as compared to the two alternatives. Moreover, it turns out that when a firm delegates while the other does not, the resulting equilibrium outcome at the market stage replicates the Cournot-Stackelberg one, with the managerial firm leading irrespective of the specific nature of the incentive scheme.

In this note, we show that this result, common across the three delegation schemes, is generated by three completely different mechanisms affecting the best reply function of the managerial firm.

\section{The three market subgames}

The model describes a homogeneous good duopoly with inverse demand function $p=a-Q$, where $Q=q_{1}+q_{2}$ is aggregate output, $q_{i}$ is the individual quantity of firm $i$ and $a$ is a positive parameter. Both firms use the same

\footnotetext{
${ }^{1}$ See, for instance, Aggarwal and Samwick (1999).
} 
technology described by the cost function $C_{i}=c q_{i}$, with $c \in(0, a)$. For the sake of simplicity, we pose $a-c=A$. Firms are quantity-setting agents and move simultaneously at the market stage.

The baseline models tackling the separation between ownership and control for strategic reasons share a three-stage structure, where information is complete, symmetric and imperfect in every stage, while being perfect between any two adjacent stages. At the first stage, owners decide whether to delegate or not; at the second, if they do, they tune the incentives subministered to their own managers; at the third stage, managers or owners play a Cournot game. In every stage, players behave noncooperatively. Contracts are fully observable.

In general, the incentive given to a firm's manager consists in a combination of her/his firm's profits and something else. So far, three alternatives have been accounted for:

- output level (as in Vickers, 1985) or revenues (Fershtman, 1985; Fershtman and Judd, 1987; and Sklivas, 1987), which are indeed equivalent (Lambertini and Trombetta, 2002). We will refer to this scheme as $V F J S$;

- market share (Jansen et al. 2007; and Ritz, 2008), JR henceforth;

- comparative performance, whereby the manager has to maximise a weighted average of her/his firm's profits and the rival's (Salas Fumas, 1992; Lundgren, 1996; Aggarwal and Samwick, 1999; and Miller and Pazgal, 2001), MP in the remainder.

We now examine the three specific objective functions of managers and the bearings of each type of incentive on Cournot competition in the market stage. 


\subsection{Delegation based on output level}

In $V F J S$, the manager of firm $i$ chooses output to maximise $M_{i}=\pi_{i}+\theta_{i} q_{i}$, where $\theta_{i}$ is the weight attached to output, to be specified in the delegation contract at the second stage by firm $i$ 's owner. The effect of this incentive on firm $i$ 's behaviour in the market stage is captured by a parallel shift of the same firm's linear reaction function in the output space (see Figure 1). The optimal unilateral shift reproduces the Cournot-Stackelberg outcome with the managerial firm as the leader.

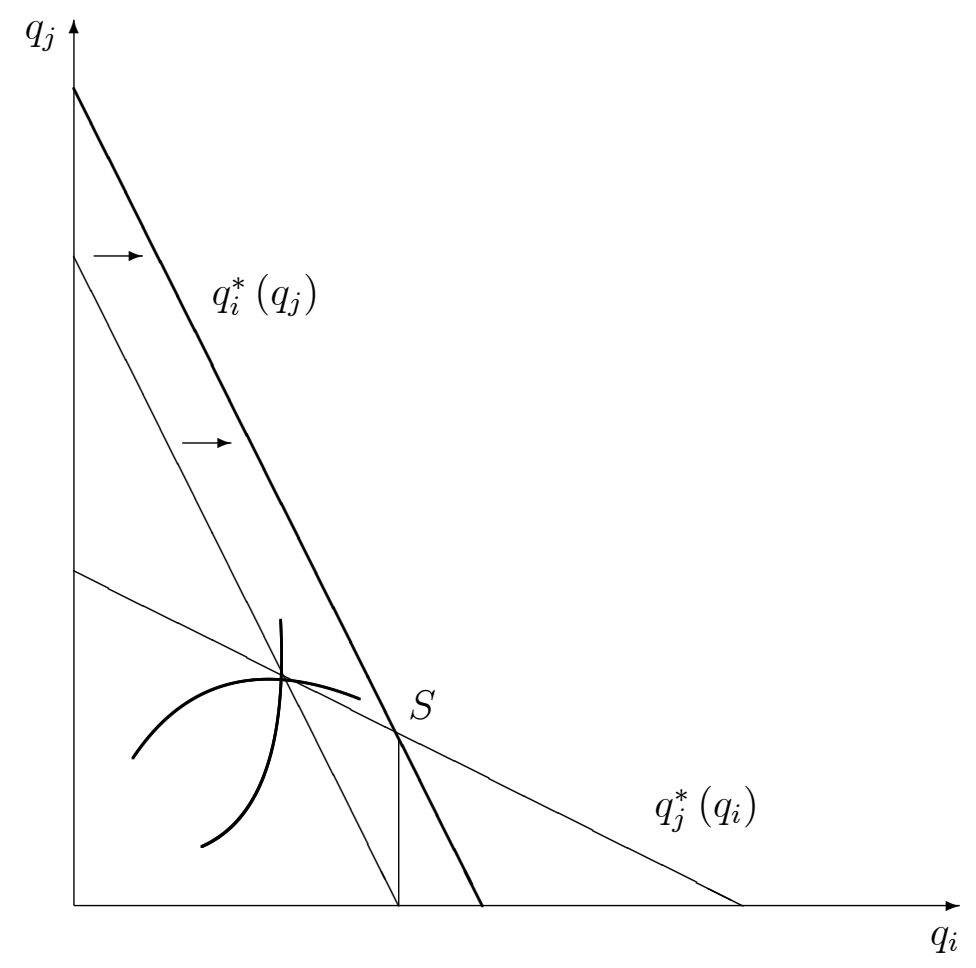

Figure 1 Unilateral delegation as in VFJS

In Figure 1, the thin best replies are those characterising the Cournot game among entrepreneurial firms. The isoprofit curves at their intersection are also drawn. The thick line is firm $i$ 's reaction function when a manager 
controls its output. The outward parallel shift is indicated by horizontal arrows. The interception between the managerial reaction function and the entrepreneurial one (point $S$ ) identifies the Stackelberg equilibrium in the output space.

\subsection{Delegation based on market share}

If an incentive based on market share is adopted, as in $J R$, the manager's maximand becomes $M_{i}=\pi_{i}+\theta_{i} q_{i} /\left(q_{i}+q_{j}\right)$. The resulting first order condition (FOC) is

$$
\frac{\partial M_{i}}{\partial q_{i}}=A-2 q_{i}-q_{j}+\frac{\theta_{i}}{q_{i}+q_{j}}\left(1-\frac{q_{i}}{q_{i}+q_{j}}\right)=0
$$

which produces a best reply function $q_{i}^{*}\left(q_{j}\right)$ concave in $q_{j}$. If firm $j$ hasn't hired a manager (i.e., $\theta_{j}=0$ ), its best reply is the standard linear Cournot reaction function. Notice that, if $q_{j}=0,(1)$ is satisfied by $q_{i}=A / 2$, which is the Stackelberg leader's output. The nonlinear component in the r.h.s. of (1) must be concave for all $q_{j}>0$ in order for firm $i$ 's best reply to bend back and intersect firm $j$ 's best reply at $q_{i}=A / 2$.

As illustrated in Figure 2, the two reaction functions actually intersect in correspondence of the Stackelberg equilibrium with the managerial firm once again playing the leader's role, with $\theta_{i}=2(5 \sqrt{2}-1) A^{2} / 49$. Here, the reaction function of the managerial firm is the thick concave curve departing from the horizontal axis at the monopoly output level and intersecting the entrepreneurial firm's best reply in correspondence of the same output in point $S$. 


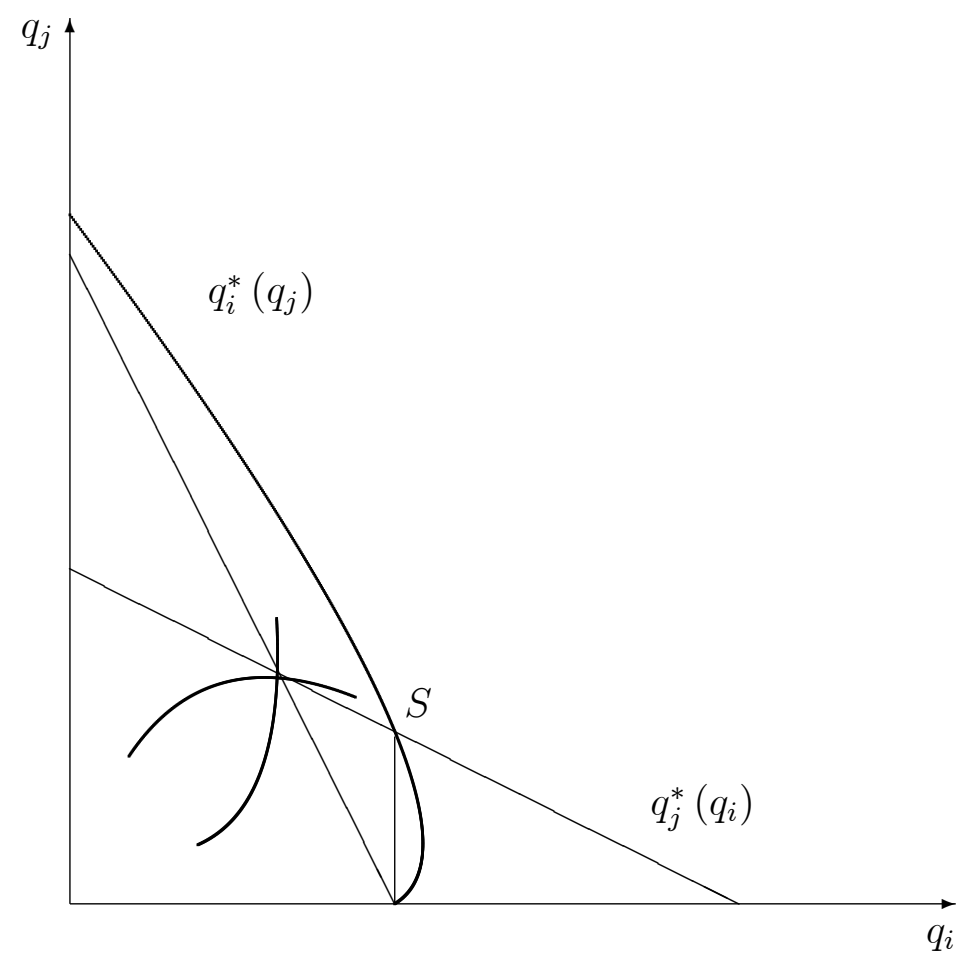

Figure 2 Unilateral delegation as in $J R$

\subsection{Delegation based on comparative performance}

In $M P$, the objective function of the manager of firm $i$ is $M_{i}=\pi_{i}+\theta_{i} \pi_{j}$. The FOC taken on $q_{i}$ yields a best reply function

$$
q_{i}^{*}\left(q_{j}\right)=\frac{A-\left(1+\theta_{i}\right) q_{j}}{2}
$$

from which it is evident that delegation modifies the slope. If the rival has no manager, the optimal contract sets $\theta_{i}=-1$ in such a way that $q_{i}^{*}\left(q_{j}\right)$ becomes flat at the Stackelberg leader's output, as depicted in Figure 3. This is the consequence of the fact that here, while the delegation scheme is nonlinear, it generates a best reply which is linear in $q_{j}$, where delegation rotates the 
reaction function of the managerial firm. Hence, in order to reproduce the Cournot-Stackelberg equilibrium, the owner must provide the meneger with a dominant strategy at the market subgame.

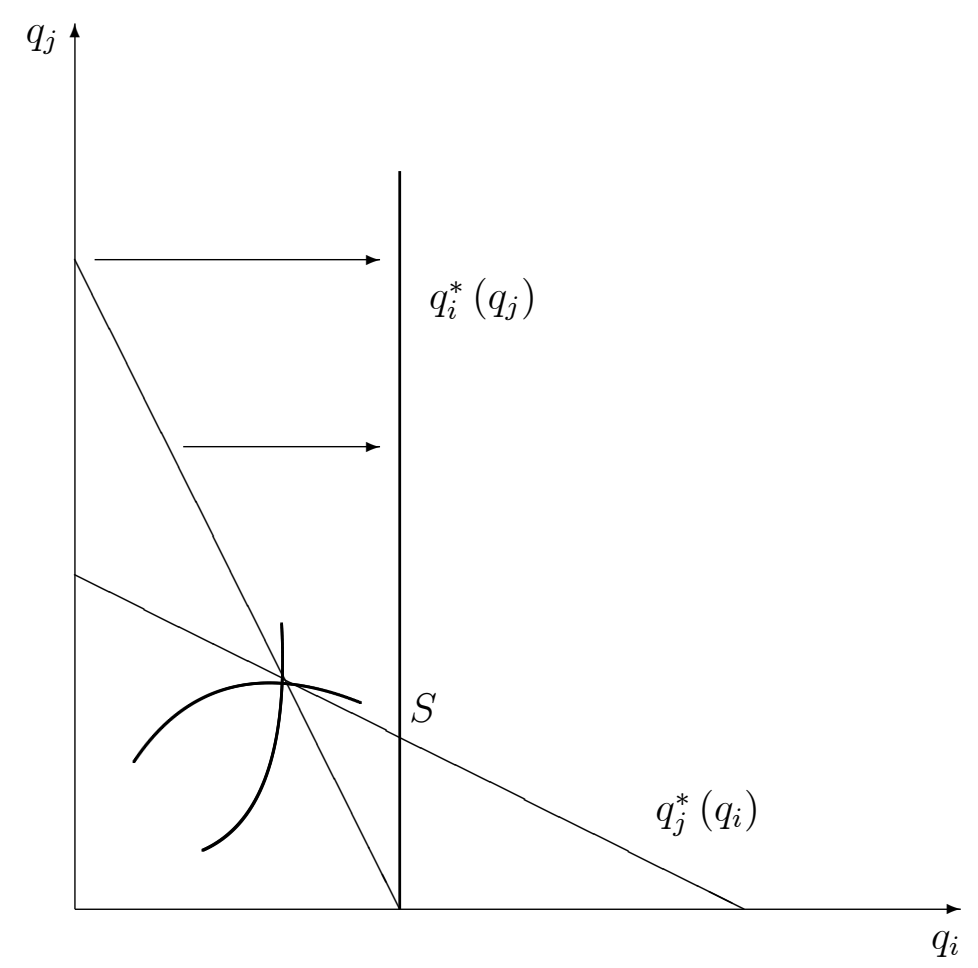

Figure 3 Unilateral delegation as in $M P$

The foregoing discussion produces then the following

Proposition 1 As far as the market stage is concerned, if one firm delegates control to a manager while the other doesn't, the choice of the incentive scheme in the set $\{V F J S, J R, M P\}$ is immaterial as the outcome systematically replicates the Cournot-Stackelberg equilibrium with the managerial firm leading.

A straightforward implication of this result is that, if one observes the market subgame equilibrium only, without knowing the nature of the man- 
agerial contract, one cannot infer the exact contents of the incentive given by the owner to her/his manager. This is because, from the standpoint of market allocation and performance, the three contracts are indeed observationally equivalent. That is to say, if your rival is not smart enough to copycat your strategy, then literally anything goes, at least within the threefold menu used so far in this literature. 


\section{References}

[1] Aggarwal, R.K. and A.A. Samwick (1999), "Executive Compensation, Strategic Competition, and Relative Performance Evaluation: Theory and Evidence", Journal of Finance, 54, 1999-2043.

[2] Baumol, W. (1958), "On the Theory of Oligopoly", Economica, 25, 187-98.

[3] Fershtman, C. (1985), "Managerial Incentives as a Strategic Variable in Duopolistic Environment", International Journal of Industrial Organization, 3, 245-53.

[4] Fershtman, C. and K. Judd (1987), "Equilibrium Incentives in Oligopoly", American Economic Review, 77, 927-40.

[5] Jansen, T., A. van Lier and A. van Witteloostuijn (2007), "A Note on Strategic Delegation: The Market Share Case", International Journal of Industrial Organization, 25, 531-39.

[6] Jansen, T., A. van Lier and A. van Witteloostuijn (2009), "On the Impact of Managerial Bonus Systems on Firm Profit and Market Competition: The Cases of Pure Profit, Sales, Market Share and Relative Profits Compared", Managerial and Decision Economics, 30, 141-53.

[7] Lambertini, L. and M. Trombetta (2002), "Delegation and Firms' Ability to Collude", Journal of Economic Behavior and Organization, 47, 359-73.

[8] Lundgren, C. (1996), "Using Relative Profit Incentives to Prevent Collusion", Review of Industrial Organization, 11, 533-50.

[9] Miller, N.H. and A.I. Pazgal (2001), "The Equivalence of Price and Quantity Competition with Delegation", RAND Journal of Economics, 32, 284-301. 
[10] Ritz, R.A. (2008), "Strategic Incentives for Market Share", International Journal of Industrial Organization, 26, 586-97.

[11] Salas Fumas, V. (1992), "Relative Performance Evaluation of Management: The Effects on Industrial Competition and Risk Sharing", International Journal of Industrial Organization, 10, 473-89.

[12] Schelling, T. (1960), The Strategy of Conflict, Cambridge, MA, Harvard University Press.

[13] Sklivas, S.D. (1987), "The Strategic Choice of Managerial Incentives", RAND Journal of Economics, 18, 452-58.

[14] Vickers, J. (1985), "Delegation and the Theory of the Firm", Economic Journal, 95 (Conference Papers), 138-47. 


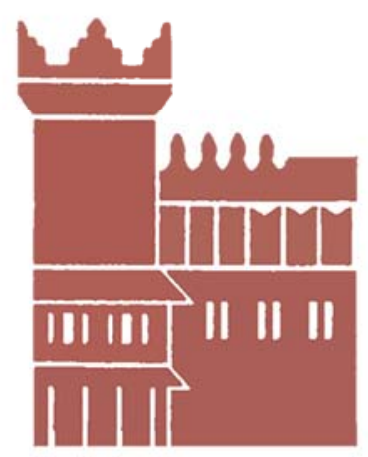

Alma Mater Studiorum - Università di Bologna DEPARTMENT OF ECONOMICS

Strada Maggiore 45

40125 Bologna - Italy

Tel. +39051 2092604

Fax +390512092664

http://www.dse.unibo.it 